\title{
$\mathbf{K}$ 均值聚类和模糊 C 聚类对黄前水库流域水文要素测报分析
}

\author{
徐珊 \\ 临沂市水文局 \\ DOI:10.32629/hwr.v4i8.3246
}

\begin{abstract}
[摘 要] 在黄前水库观测资料的基础上,运用 $\mathrm{K}$ 均值聚类和模糊 $\mathrm{C}$ 聚类的方法,对黄前水库的降雨量和水 文要素进行分析, 由于流域降水是影响黄前水库来水量的最重要的影响因素,建立了水库来水量与流域 降水量之间的线性关系。这些分析结果对黄前水库的合理开发与利用有指导作用。

[关键词] K均值聚类; 模糊C聚类; 黄前水库流域; 水文要素测报分析 中图分类号：TV75 文献标识码：A
\end{abstract}

\section{1 黄前水库概况}

地理位置: 黄前水库位于泰安市岱 岳区泰山东麓, 东经 $116^{\circ} 20^{\prime} \sim 117^{\circ}$ $59^{\prime}$, 北纬 $35^{\circ} 38^{\prime} \sim 36^{\circ} 28^{\prime}$, 水源由 泰山、长清岭和大青山的三条溪流汇聚 而来, 流域为扇形, 控制流域面积为 $292 \mathrm{~K}$ $\mathrm{m}^{2}$, 多年平均来水量 6000 万 $\mathrm{m}^{3}$ 。

气候条件: 库区属暖温带大陆性半湿 润季风气候, 多年平均气温 $18.5^{\circ} \mathrm{C}$, 年平 均降雨量 $758 \mathrm{~mm}, 75 \%$ 的降雨量集中于 $6-9$ 月份, 最大年降雨量 $1303 \mathrm{~mm}$ (1964年), 连 续 3 日暴雨量 $238.6 \mathrm{~mm}$, 最小年降雨量 $334.4 \mathrm{~mm}$ (1989年), 多年平均径流深 $254 \mathrm{~mm}$ 。

工程概况: 黄前水库于1958年动工兴 建, 1960年建成蓄水, 水库位于泰安市岱 岳区北部黄前镇, 坝址以上控制流域面积 $292 \mathrm{~km}^{2}$, 总库容 $8248 \times 104 \mathrm{~m}^{3}$, 兴利库容 $5913 \times 104 \mathrm{~m}^{3}$ 。黄前水库防洪标准为 1983 年水利工程三查三定洪水复核结果: 百年 一遇设计, 三日净雨 $317.1 \mathrm{~mm}$, 最高库水位 209. 0m, 千年一遇校核, 三日净雨 $486 \mathrm{~mm}$, 最高库水位 $210.65 \mathrm{~m}$, 可能最大降雨校核, 三日净雨 $1014.5 \mathrm{~m}$, 最高库水位 $212.17 \mathrm{~m}$, 兴利水位 $209.0 \mathrm{~m}$, 死水位 $190.60 \mathrm{~m}$ 。

黄前水库位于大汶河流域上游, 黄 前水库流域降雨及水库状况又与流域水 文地质、水体自净能力等方面密切相关, 同时, 工农业生产的快速发展使流域水 资源开发利用程度过高, 水文情势改变 较大, 增加了水环境变化的不确定因素。 因此, 水库流域要素研究十分复杂。
目前, 黄前水库流域降雨径流等水文 要素及水库调度基于水库建设以来的整 合信息路径不够清晰, 缺乏理论与实证研 究支撑, 没有研究水库流域降雨关联要 素、水库变化因子整合预测模型, 无法形 成针对性的整合行动目标; 流域降雨的整 体趋势把握不够, 且主要采用传统的分析 方法解决问题等。因此, 无论是把握降雨
径流变化规律, 还是科学解决水资源开发 利用与流域生态水利建设环境之间的矛 盾, 实现水库及流域可持续开发利用都具 有重要的理论和实践意义。

\section{2 流域降雨变化特征}

黄前水库流域有五个雨量监测站: 独 路、彭家峪、下港、西麻塔和黄前水 库, 1964年至2012年的年降雨量如图2-1。

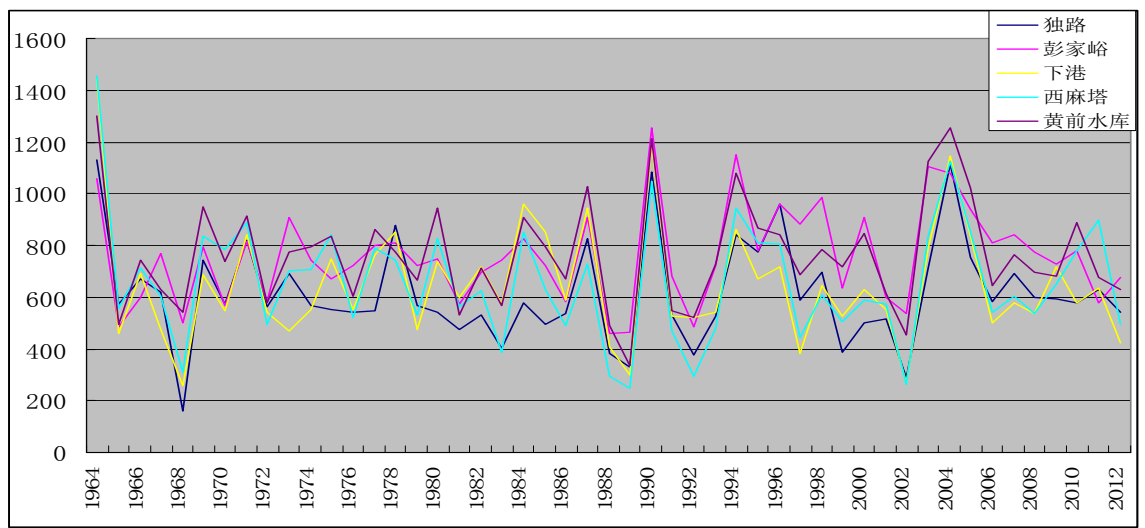

图 2-1 五站年降雨量对比

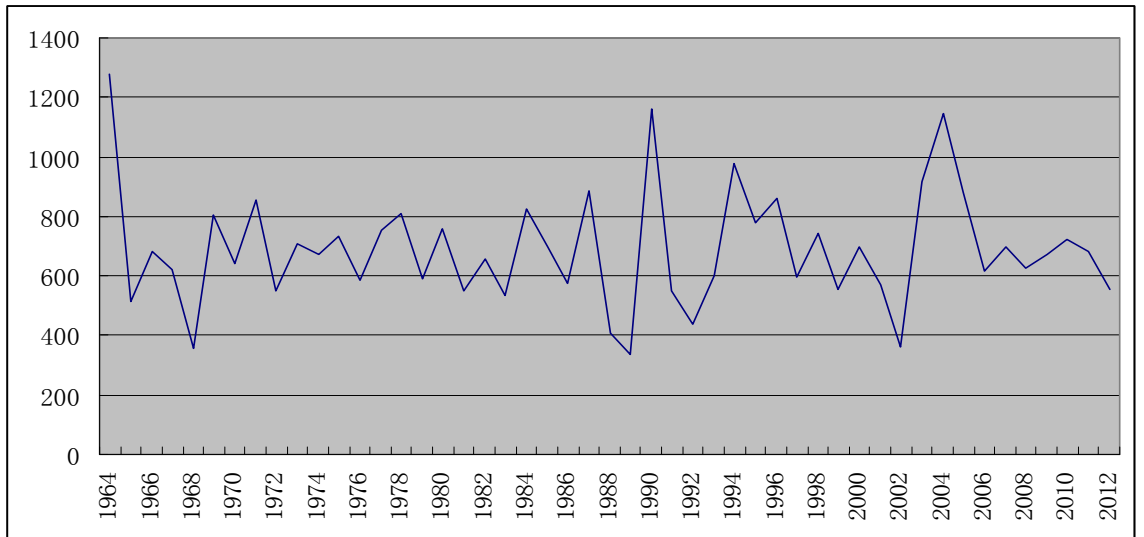

图 2-2 五站年降雨量均值 
从图2-1至图2-2年降雨量变化情 况分析得出, 独路、彭家峪、下港、西 麻塔和黄前水库五站监测降雨量具有 如下特点:

(1) 降雨量具有同步性。

(2) 各站降雨量大小没有确切的排 列顺序。

(3) 多年降雨量变化幅度区间基本 稳定。

（4）没有出现过连续多年的高峰、低谷。

(5) 五站均值变化代表性与各站一致。

3 聚类分析黄前水库流域水文 要素

聚类分析的目的是把分类对象按照 一定规则分成若干类, 这些类不是事先 给定的, 而是根据数据的特征确定的, 对 类的数目和类的结构不必作任何假定。 在同一类里的这些对象在某种意义上倾 向于彼此相似, 而在不同类里的对象倾 向于不相似。聚类属于无监督学习, 同回 归、朴素贝叶斯、SVM等都是有类别标签 的, 而聚类的样本中却没有给定类别, 只 有表示特征的数据列。因此, 通过对于黄 前水库流域水文特征要素进行聚类分析, 对水文要素进行测报, 是一种科学的发 现潜在规律的方法。

$3.1 \mathrm{~K}$ 均值聚类黄前水库流域水文 要素测报分析

将独路、彭家峪、下港、西麻塔和 黄前水库五站的年降雨作为输入参数进 行 K聚类, 也就是将黄前水库流域降雨五 站监测的降雨量统筹考虑进行聚类分析, 评判历年和每年的降雨情况。

1964-2012年五站年降雨量K聚类分 析设置最终分类从 3 类开始, 在程序设计 时自动分类到 6 类, 以后可以根据水文监 测的需要调整分类, 模型运行后每一分 类情况如下:

\section{六类分法K均值聚类的轮廓图}

通过以上 $K$ 聚类分析得出结论如下:

(1) 使用 K均值聚类分析降雨等水文 要素, 适用于选择事先约定的标准降雨 量作为初始凝聚点, 这样根据约定的分 类数目和初始凝聚点, 然后运行聚类模 型, 得到十分满意的效果。

(2) 分类不宜过粗或过细, 采用 5 类

(1)设置最终分类个数为 3 类时:

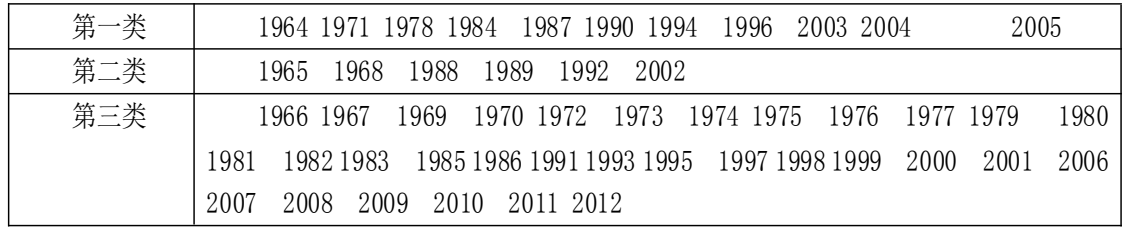

(2)设置最终分类个数为 4 类时:

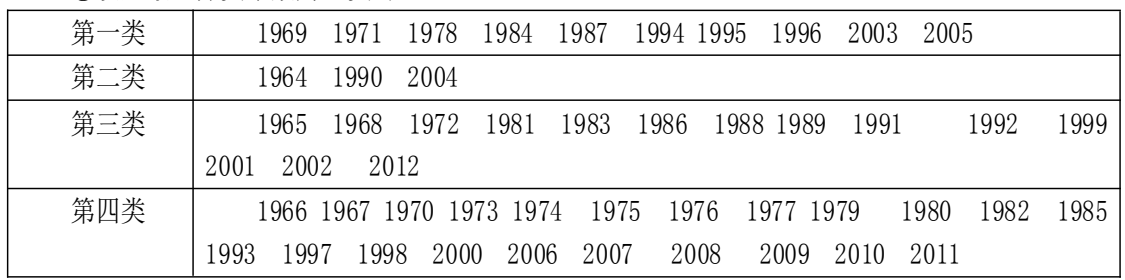

(3)设置最终分类个数为 5 类时:

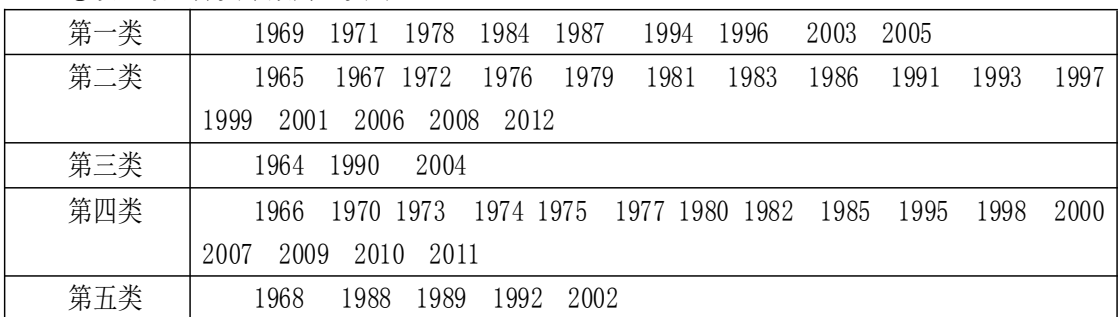

(4) 设置最终分类个数为 6 类时:

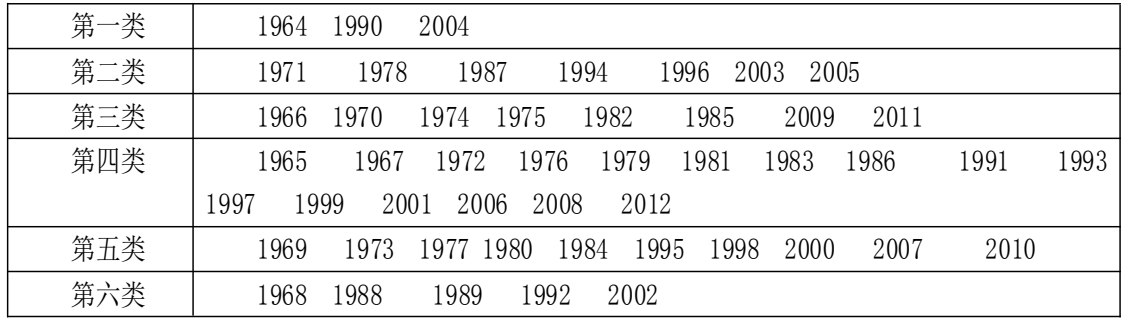

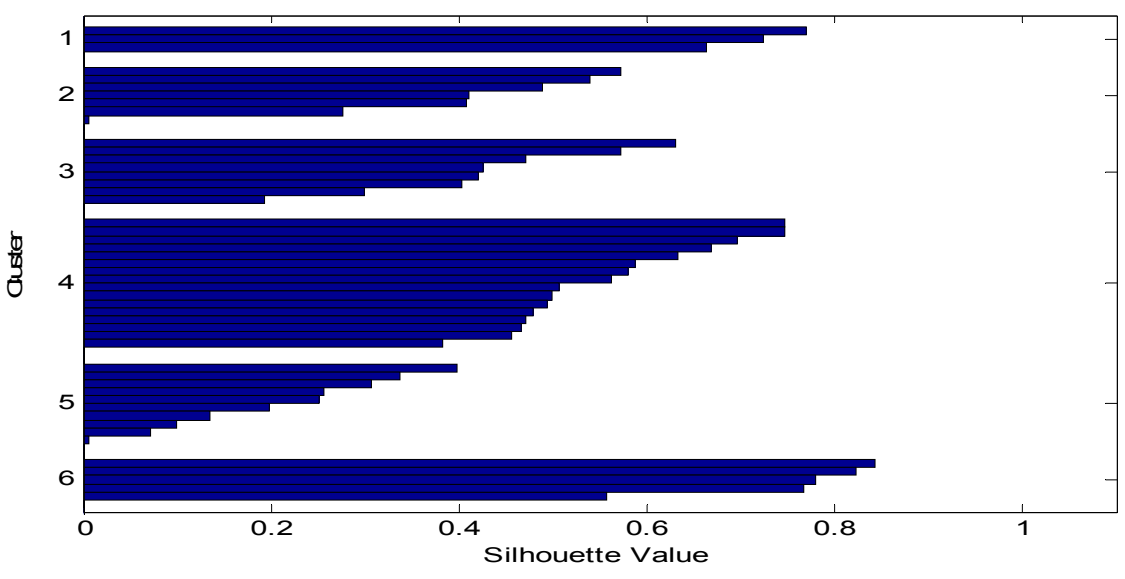

六类分法 $\mathrm{K}$ 均值聚类的轮廓图

或6类较合适。6 类分法可以描述为, 全年 降雨量与历年比较为: 大、较大、中、 一般、较小和小。比如, 对 2012 年降雨采 用6类分法, 测报为 “黄前水库流域全年 降雨为一般水平”。

(3) 采用五站降雨综合评判, 能够较 全面反映黄前水库流域历年降雨特征,
水库流域归类比较系统, 特别是为今后 水库调度提供基准比较案例决策支持。

(4) 建立地区型和流域内 $K$ 聚类分析 比较对于区域水资源管理提供更加具体 的决策数据。

3.2 模糊 $\mathrm{C}$ 聚类黄前水库流域水文要 素测报分析 
模糊 C-均值聚类算法fuzzy c-means algorithm(FCMA) 或称 (FCM), 作为无监督 机器学习的主要技术之一, 是用模糊理 论对重要数据分析和建模的方法, 建立 了样本类属的不确定性描述, 能比较客 观地反映现实世界, 它已经有效地应用 在大规模数据分析、数据挖掘、矢量量 化、图像分割、模式识别等领域, 具有重 要的理论与实际应用价值, 随着应用的 深入发展, 模糊聚类算法的研究不断丰 富。在众多模糊聚类算法中, 模糊 $\mathrm{C}$-均值 (FCM) 算法应用最广泛且较成功, 它通 过优化目标函数得到每个样本点对所 有类中心的隶属度, 从而决定样本点的 类属以达到自动对数据样本进行分类 的目的。FCM算法为, FCM 把 $\mathrm{n}$ 个向量 xi $(i=1,2, \cdots, n)$ 分为c 个模糊组, 并求每 组的聚类中心, 使得非相似性指标的价 值函数达到最小。FCM与HCM的主要区别 在于FCM用模糊划分, 使得每个给定数据 点用值在 0,1 间的隶属度来确定其属于 各个组的程度。与引入模糊划分相适应, 隶属矩阵U允许有取值在 0,1 间的元素。 不过, 加上归一化规定,一个数据集的隶 属度的和总等于 1. FCM的价值函数(或目 标函数) 就是所有个点隶属度乘以该点 与中心的欧氏距离之和。在批处理方式 运行时, FCM用下列步骤确定聚类中心ci 和隶属矩阵 $\mathrm{U}$ 。

步骤1: 用值在 0,1 间的随机数初始化 隶属矩阵U, 使其满足设定的约束条件。

步骤 2 : 计算 $c$ 个聚类中心 $c i, i=1$, $\cdots, \mathrm{c}$ 。

步骤 3 : 计算价值函数。如果它小于 某个确定的阀值, 或它相对上次价值函数 值的改变量小于某个阀值, 则算法停止。

步骤 4 : 计算新的U矩阵。返回步骤 2 。

上述算法也可以先初始化聚类中 心, 然后再执行迭代过程。由于不能确 保FCM收敛于一个最优解。算法的性能 依赖于初始聚类中心。因此, 我们要么

(1)模糊 $\mathrm{C}$ 聚类自动分类为 5 类时:

\begin{tabular}{|c|cccccccccc|}
\hline 第一类 & 1964 & 1990 & 2004 & 7002 & & & & \\
\hline 第二类 & 1968 & 1988 & 1989 & 1992 & 2002 & 1998 \\
\hline 第三类 & 1969 & 1971 & 1978 & 1984 & 1987 & 1994 & 1995 & 1996 & \\
& 2003 & 2005 & & & & & & & \\
\hline 第四类 & 1966 & 1970 & 1973 & 1974 & 1975 & 1977 & 1980 & 1982 & 1985 \\
& 2000 & 2007 & 2009 & 2010 & 2011 & & & & \\
\hline 第五类 & 1965 & 1967 & 1972 & 1976 & 1979 & 1981 & 1983 & 1986 & 1991 \\
& 1993 & 1997 & 1999 & 2001 & 2006 & 2008 & 2012 & & \\
\hline
\end{tabular}

(2)模糊 C 聚类自动分类为 6 类时:

\begin{tabular}{|c|cccccccccccc|}
\hline 第一类 & 1964 & 1990 & 2004 & & & & \\
\hline 第二类 & 1966 & 1974 & 1975 & 1977 & 1980 & 1985 & 1995 & 1998 & 2000 & 2010 & 2011 \\
\hline 第三类 & 1965 & 1970 & 1972 & 1976 & 1981 & 1983 & 1986 & 1991 & 1999 & 2001 & 2012 \\
\hline 第四类 & 1969 & 1971 & 1978 & 1984 & 1987 & 1994 & 1996 & 2003 & 2005 & & \\
\hline 第五类 & 1968 & 1988 & 1989 & 1992 & 2002 & & & & & \\
\hline 第六类 & 1967 & 1973 & 1979 & 1982 & 1993 & 1997 & 2006 & 2007 & 2008 & 2009 & \\
\hline
\end{tabular}

2003 年-2012 年隶属度值:

\begin{tabular}{|l|l|l|l|l|l|l|l|l|l|}
\hline 0.1580 & 0.8199 & 0.0865 & 0.0339 & 0.0535 & 0.0191 & 0.0467 & 0.0522 & 0.0697 & 0.0371 \\
\hline 0.1912 & 0.0399 & 0.1532 & 0.1199 & 0.2323 & 0.0764 & 0.2572 & 0.4069 & 0.2489 & 0.1148 \\
\hline 0.1165 & 0.0295 & 0.0771 & 0.1982 & 0.1699 & 0.1240 & 0.2266 & 0.1369 & 0.2176 & 0.3600 \\
\hline 0.3155 & 0.0562 & 0.5421 & 0.0751 & 0.1490 & 0.0445 & 0.1195 & 0.1541 & 0.1508 & 0.0741 \\
\hline 0.0800 & 0.0223 & 0.0488 & 0.0769 & 0.0780 & 0.0413 & 0.0808 & 0.0685 & 0.1106 & 0.1303 \\
\hline 0.1389 & 0.0322 & 0.0923 & 0.4959 & 0.3173 & 0.6947 & 0.2693 & 0.1814 & 0.2024 & 0.2837 \\
\hline
\end{tabular}

用另外的快速算法确定初始聚类中 心, 要么每次用不同的初始聚类中心 启动该算法, 多次运行FCM对历年降雨 等水文要素进行测报, $K$ 聚类可以进行 动态分析, 当然历年数据系列对象间 没有明确的界限, 往往具体亦此亦彼 的表现, 如果严格划分到某类存在一 定的不合理性。因此, 使用模糊聚类分 析处理这类问题, 在模糊划分中, 每一 个样品不是严格地划分为某一类, 而 是以一定的隶属度属于某一类。

2012 年隶属度最大值为 0.3600 , 化 为第三类。

通过以上模糊 $\mathrm{C}$ 聚类分析得出结论 如下:

(1) 使用模糊 C聚类分析降雨等水文 要素, 适用于从归类隶属度大小分析历 年降雨量序列, 自动决定类别, 得到最好 的隶属度分类效果。

(2) 同样, 分类不宜过粗或过细, 采 用5类或6类较合适。6 类分法可以描述为,
全年降雨量与历年比较为: 大、较大、 中、一般、较小和小。比如, 对2012年降 雨采用6类分法, 测报为 “黄前水库流域 全年降雨为一般水平”。

(3) 采用五站降雨综合评判, 能够较 全面反映黄前水库流域历年降雨特征, 水库流域归类比较系统, 特别是为今后 水库调度提供基准比较案例决策支持。

(4) 和 $K$ 聚类互相比较, 建立地区型 和流域内模糊 $\mathrm{C}$ 聚类分析比较对于区域 水资源管理提供更加具体的决策数据。

\section{[参考文献]}

[1]周凯慧,刘霞,李化民,等.黄前水 库水质监测及变化规律研究 [J].水土保 持学报,2004(04):150-153+157.

[2]张春荣, 高宗军.黄前水库来 水量特征与影响因素分析 [J]. 地下 水,2008(03):74-77.

[3]杨雪,赵得玉,申正涛,等.清水河 降水分布特征及影响因素分析[J].湖北 农机化,2019(05):64. 